Published in final edited form as:

J Am Chem Soc. 2005 September 7; 127(35): 12254-12262.

\title{
Engineered Biosynthesis of Aklanonic Acid Analogs
}

\author{
Taek Soon Lee ${ }^{1}$, Chaitan Khosla ${ }^{1,2,3,{ }^{*} \text {, and } \mathrm{Yi} \text { Tang }}{ }^{4}$ \\ 1 Department of Chemistry, \\ 2 Chemical Engineering, and \\ 3 Biochemistry, Stanford University, Stanford, California 94305 \\ 4 Department of Chemical Engineering, University of California at Los Angeles, Los Angeles, CA, \\ 90095
}

\section{Abstract}

Aklanonic acid, an anthraquinone natural product, is a common advanced intermediate in the biosynthesis of several antitumor polyketide antibiotics, including doxorubicin and aclacinomycin A. Intensive semisynthetic and biosynthetic efforts have been directed toward developing improved analogs of these clinically important compounds. The primer unit of such polyfunctional aromatic polyketides is an attractive site for introducing novel chemical functionality, and attempts have been made to modify the primer unit by precursor directed biosynthesis or protein engineering of the polyketide synthase (PKS). We have previously demonstrated the feasibility of engineering bimodular aromatic PKSs capable of synthesizing unnatural hexaketides and octaketides. In this report we extend this ability by preparing analogs of aklanonic acid, a decaketide, and its methyl ester. For example, by recombining the R1128 initiation module with the dodecaketide-specific pradimicin PKS, the isobutyryl primed analog of aklanonic acid (YT296b, 10) and its methyl ester (YT299b, 12) were prepared. In contrast, elongation modules from dodecaketide-specific spore pigment PKSs were unable to interact with the R1128 initiation module. Thus, in addition to revealing a practical route to new anthracycline antibiotics, we also observed a fundamental incompatibility between antibiotic and spore pigment biosynthesis in the actinomycetes bacteria.

\section{Introduction}

Aklanonic acid, a member of the polyketide family of natural products ${ }^{1,2}$, is an anthraquinone compound and a biosynthetic precursor of several important antibiotics including daunorubicin, baumycin A1, nogalamycin, and the anticancer drugs doxorubicin and aclacinomycin A (Figure 1(A), Figure 2). The primary differences between these natural products lie in their substitution patterns, especially their glycosylation patterns. Over the past few decades there have been intensive attempts to prepare semi-synthetic analogs of this family of compounds. ${ }^{3}$ (Figure 1(B)) For example, anthracyclines containing a disaccharide chain with substitutions at 4 '-hydroxy group or a monosaccharide with methoxymorpholino ring (PNU152243) have shown promising activity. ${ }^{4,5}, 6$ Similarly, removal of the 4-methoxy group from certain anthracyclines resulted in increased drug activity. 7,8 The C-9 side chain has also been modified with or without reduction of the carbonyl group. ${ }^{9,10,11}$ At least one of these analogs (MEN10755) is currently in clinical trials. ${ }^{3}$

*To whom correspondence should be addressed: Chaitan Khosla, Department of Chemistry, Chemical Engineering, and Biochemistry, Stanford University, Stanford, CA 94305. E-mail: khosla@ stanford.edu.

Supporting Information Available. Physical maps of plasmids pYT266, pYT292, pYT296 and pYT299. HPLC traces for CH999/ pYT227, CH999/pYT226, CH999/pYT236, CH999/pYT231, CH999/pYT243, CH999/pYT266, CH999/pYT292, CH999/pYT296, CH999/pYT299 with peak assignment by LC/MS. 
Much has been learned within the past two decades about the biosynthesis of anthracycline natural products through the combined exploitation of chemical, biochemical and genetic approaches. ${ }^{4,12,13}$ These insights have started to yield practical benefits; for example, a bacterium has been engineered to synthesize epirubicin, a clinically important semi-synthetic analog of doxorubicin with reduced side effects. ${ }^{14}$ (Figure 1(B)) Notwithstanding this progress, an even greater diversity of biosynthetic anthracyclines can be realized when the polyketide backbones of these natural products are systematically modified. Here we describe a new strategy for achieving this goal.

The primer unit in aromatic polyketide biosynthesis is an attractive site for introducing novel chemical functionality into existing natural products. ${ }^{15}$ In the absence of a dedicated mechanism for introducing non-acetyl primer units, the minimal PKS, comprising a ketosynthase (KS), a chain length factor (CLF), an acyl-carrier protein (ACP) and a malonylCoA:ACP transacylase (MAT), decarboxylates one malonyl equivalent and initiates polyketide assembly with an acetyl group. ${ }^{16,17,18}$ However, certain natural products, such as doxorubicin, wailupemycin and the R1128, estrogen receptor antagonists, can incorporate various non-acetyl primers, such as propionate, benzoate and a range of short-chain fatty acids, into their backbones. (Figure 3) ${ }^{12,19,20,21}$ In some cases, such as the R1128 PKS and the daunorubicin PKS, the synthase includes a dedicated module of enzymes for chain initiation. 22,23 Recent studies have demonstrated that these initiation modules can collaborate with elongation modules from heterologous octaketide synthases and decaketide synthases to produce non-acetyl primed hexaketide and octaketide natural products, respectively. ${ }^{24}$ In each case, chain length of the polyketide backbone is dictated by the elongation module (i.e., the minimal PKS). Since the anthracycline antitumor antibiotics shown in Figure 1(A) are decaketides, it was therefore hypothesized that primer unit modifications of this class of natural products would require the use of a dodecaketide PKS. Specifically, we targeted the engineering of aklanonic acid and aklanonic acid methyl ester analogs, since these compounds are the first common stable intermediates in the biosynthesis of the antitumor compounds shown in Figure 1(A).

Several dodecaketide synthases have been reported in the literature. For example, the spore pigment PKSs from various Streptomyces species, including whiE from S. coelicolor ${ }^{25}$, sch from $S$. halstedii, and cur from S. curacoi, synthesize dodecaketide backbones. ${ }^{26,27}$ The pradimicin PKS from Actinomadura hibisca has also been identified as a dodecaketide synthase. ${ }^{28}$ Although our initial efforts to prepare aklanonic acid analogues attempted to harness the spore pigment PKSs, we observed a fundamental incompatibility between the R1128 initiation module and the spore pigment elongation modules. We therefore harnessed the pradimicin KS-CLF to successfully produce a range of aklanonic acid analogs in good yield. In addition to providing a route to new antitumor compounds, our results highlight the biochemical logic of PKS specificity during contemporaneous antibiotic and spore pigment synthesis in the life cycle of an actinomycete bacterium.

\section{Experimental Methods}

\section{Materials}

Silica gel plates Si250F for thin layer chromatography were obtained from J. T. Baker. All other chemicals and solvents were purchased from Sigma, Aldrich, and Fisher Scientific and were of the highest available grade.

\section{Bacterial Strain and General Methods for DNA Manipulation}

S. coelicolor strain $\mathrm{CH} 999$ was used as the host for transformation by shuttle vectors. Protoplast preparation and PEG-assisted transformation were performed as described by Hopwood et al. 
29 All cloning steps were performed in Escherichia coli strain XL-1 Blue (Stratagene). PCR was performed using PfuTurbo polymerase (Stratagene). PCR products were first cloned into a pCR-Blunt vector (Invitrogen) followed by DNA sequencing (Stanford PAN Facility). Unmethylated DNA was obtained using the methylase-deficient strain GM2163 (New England Biolabs). T4 DNA ligase (Invitrogen) was used for ligation of restriction fragments.

\section{Construction of Plasmids}

The following primers were used to amplify the individual genes: Sch KS: 5'-

GATTAATTAAGGAGGAGCCATCATCATGAGCCGCCGGGTCGTCGTCACCGG-3', 5'CGATGCATTCATCTCAGCCTCCTCTCCGGTCCGG-3' (PacI/NsiI); Sch CLF: 5'GAATGCATGGAGGAGCCATCATGAGCGCACCCCGGCGAGCCGTCG-3' (NsiI); whiE ACP: 5'-CCTCTAGAGGAGGAGCCCATATGACCGATCAGCAGCTGGAC-3', 5'GGACTAGTCCACTCCCGTCTTGAGGGCGCC-3' (XbaI,NdeI/SpeI); whiE cyclase: 5'GCACTAGTGCCCTCAAGACGGGAGTGTGACATG-3' (SpeI); Pms KS: 5'GATTAATTAAGGAGGAGCCATCATGAGCCGACCGCAGGGGGGCGGG-3', 5'GGATGCATCATGCGGCCTCCCGCAGGACGG-3' (PacI/NsiI); Pms CLF: 5'GGATGCATGGAGGAGCCATCATGAGCGTCCTGACGGCGGACGCGCCGG-3', 5'GGTCTAGAGGTCAGGTGTTCGGGCCGCGCAGCACC-3' (Nsil/XbaI); Pms ACP: 5'GGTCTAGAGGAGGAGCCCATATGGCAACCCGCGAACGCACCATCG-3', 5'GGACTAGTCATCGCTCGGCCACCGCCCGCCCG-3' (XbaI,NdeI/SpeI); Pms CYC: 5'GGACTAGTGGAGGAGCCATCATGACGCAGCTGGCGCACCGACAGCG-3', 5'GGTCACCGCGCGCCCCGGGCCGCCCG-3' (SpeI); gris ARO/CYC: 5'GGTTTAAACGGAGGAGCCAGCATGTCGCAGCCCGGCCTGCGCGAGG-3', 5'GGACTAGTCAGCCCCGCCGGCCCGCGGCACG-3' (PmeI/SpeI); $d p s Y$ CYC: 5'GGACTAGTGGAGGAGCCAGCATGTGCTGTGGTGGCCCGAGAGGAG-3', 5'CATCCTAGGAATTAGCTAGCTCATTCGTCGACGAAGGCGACCG-3' (SpeI/ NheI,AvrII); $d n r G$ oxidase: 5'-

GATGCTAGCGGAGGAGCCAGCATGCCACAGCCAGAACCGAACGACG-3', 5'CATCCTAGGAATATCACGTCGTCCGCCCTCCGGGCCCG-3' (NheI/AvrII); $d n r C$ methyl esterase: $5^{\prime}-$ GGCCTAGGAGGAGCCAGCATGCAGGATTCGTCCTACAAAGAG-3', 5'GGTCAGTGGGCGACCCGGGCGGTGACG-3' (AvrII); $d n r D$ cyclase: 5'GGCCTAGGAGGAGCCAGCATGAGCACGCAGATCGATCTGGTCCG-3', 5'GGACTAGTCAGGGGCGCCAGCCCTCGGGGGTGGG-3' (AvrII/SpeI). The introduced restriction sites are shown in italics and indicated in parentheses. Genes encoding sch KS and CLF were amplified from pIJ4301, ${ }^{30}$ and genes encoding whiE ACP and cyclase were amplified from pIJ4296. ${ }^{30}$ Genes encoding pms KS, CLF, ACP, and CYC were amplified from the genomic DNA of Actinomadura hibisca P157-2. ${ }^{28}$ Genes encoding gris ARO/CYC were amplified from pIJ5216. ${ }^{31}$

Genes encoding $d p s Y \mathrm{CYC}, \operatorname{dn} r G$ oxidase, and $\operatorname{dn} r C$ methyl esterase were amplified from the genomic DNA of $S$. peucetius. ${ }^{32,33}$ Different combinations of cassettes, as shown in Table 1, were introduced into either pYT127 (KR-R1128 initiation module) or pYT128 (R1128 initiation module without KR) to yield the corresponding constructs. ${ }^{24}$ The physical maps of plasmids pYT266, pYT292, pYT296 and pYT299 are described in Figure 5.

\section{Culture Conditions, Extractions, and Small-scale Analysis}

Strains were grown on R5 media plates 29 containing $50 \mathrm{mg} / \mathrm{L}$ thiostrepton at $30{ }^{\circ} \mathrm{C}$ for $7-10$ days. For LC/MS and analytical HPLC analysis, a well-pigmented plate was chopped into fine pieces and extracted with $30 \mathrm{~mL}$ of ethyl acetate containing $1 \%$ acetic acid. The solvent was removed in vacuo and the residue was dissolved in $1 \mathrm{~mL}$ of methanol. The polyketide products were separated by analytical reverse-phase HPLC and detected at 280 and $410 \mathrm{~nm}$ using the 
Alltech Econosphere C18 column $(250 \mathrm{~mm} \times 4.6 \mathrm{~mm})$; linear gradient: $10 \%$ acetonitrile $(\mathrm{MeCN})$ in water $(0.1 \% \mathrm{TFA})$ to $60 \% \mathrm{MeCN}$ in water $(0.1 \% \mathrm{TFA})$ over 30 min with a flow rate of $1 \mathrm{~mL} / \mathrm{min}$. HPLC retention times were as follows; $\mathbf{1}: 25.3 \mathrm{~min} ; \mathbf{2}: 21.8 \mathrm{~min} ; \mathbf{3}: 24.1 \mathrm{~min}$; 4: $25.6 \mathrm{~min} ; 5$ : $30.5 \mathrm{~min}$; $: 32.6 \mathrm{~min}$; : $24.6 \mathrm{~min} ; 8: 27.7 \mathrm{~min}$; 9: $38.2 \mathrm{~min}$; 10: $38.7 \mathrm{~min}$; 11: $40.5 \mathrm{~min}$; 12: $40.8 \mathrm{~min}$; linear gradient: $40 \% \mathrm{MeCN}$ in water (0.1\% TFA) to $80 \% \mathrm{MeCN}$ in water $(0.1 \% \mathrm{TFA})$ over $30 \mathrm{~min}$ with the flow rate of $1 \mathrm{~mL} / \mathrm{min}$; 9: $22.3 \mathrm{~min} ; \mathbf{1 0}: 25.3 \mathrm{~min}$; 11: $33.8 \mathrm{~min}$; 12: $35.1 \mathrm{~min}$ (data not shown). LC/MS was performed at the Vincent Coates Foundation Mass Spectrometry Laboratory at Stanford University using a ThermoFinnigan quadrupole ion trap LC/MS system either by electrospray ionization or by atmospheric pressure chemical ionization (both positive and negative ionization).

\section{Large-scale Production and Isolation}

A sufficient number of R5 plates (40-120 plates depending on the yield of the product) streaked with the desired $\mathrm{CH} 999$ strains were incubated at $30^{\circ} \mathrm{C}$ or $7-10$ days. The plates were chopped into fine pieces and extracted with 1 to $3 \mathrm{~L}$ of ethyl acetate containing $1 \%$ acetic acid according to the number of plates. The extract was dried over sodium sulfate, and the solvent removed in vacuo. The residue was purified by short path silica gel column chromatography (eluted with 50\% ethyl acetate in hexane with $1 \%$ acetic acid), and the product containing fractions were collected for preparative reverse-phase HPLC. The solvent was removed in vacuo, and the residue was dissolved in $5 \mathrm{~mL}$ of methanol and filtered for injection in preparative reversephase HPLC column ( $250 \mathrm{~mm} \times 22.5 \mathrm{~mm}, \mathrm{C} 18$ column; Alltech Econosil). A 10\%-60\% MeCN in water $(0.1 \% \mathrm{TFA})$ gradient was used over $50 \mathrm{~min}$ with a flow rate of $3 \mathrm{~mL} / \mathrm{min}$. The solvent was removed in vacuo from the collected fractions containing the expected biosynthetic product, and the residue was dissolved in $1 \mathrm{~mL}$ of acetone to be loaded onto a preparative TLC plate. Preparative TLC's were developed in various compositions of ethyl acetate in hexane with or without $1 \%$ acetic acid, and the desired bands were excised from the TLC plate and washed with ethyl acetate for the recovery of the compound.

\section{Spectroscopic Analysis}

The ${ }^{1} \mathrm{H}$ and ${ }^{13} \mathrm{C}$ NMR spectra were obtained on Varian Inova-500 or Mercury-400 spectrometers. The ${ }^{1} \mathrm{H}$ NMR spectra were referenced at $0 \mathrm{ppm}$ with internal tetramethylsilane in $\mathrm{CDCl}_{3}$ and at $3.31 \mathrm{ppm}$ in methanol- $d_{4}$. The ${ }^{13} \mathrm{C}$ NMR spectra were referenced at $77.1 \mathrm{ppm}$ in $\mathrm{CDCl}_{3}$ and at $49.1 \mathrm{ppm}$ in methanol- $d_{4}$. Multiple bond ${ }^{1} \mathrm{H}-{ }^{13} \mathrm{C}$ connectivity was determined by proton-detected HMBC on Varian Inova-600 NMR instruments. The ${ }^{1} \mathrm{H}$ and ${ }^{13} \mathrm{C}$ NMR assignments are summarized in Tables $2-4$. Long-range ${ }^{13} \mathrm{C}-{ }^{1} \mathrm{H}$ HMBC correlation data for the compounds: 1: H4 (C2, C3, C5, C6), H8 (C6, C7, C9, C10, C12), H10 (C8, C9, C11), H14 (C6, C12, C13, C16), H20 (C18, C22), H22 (C18, C20, C24), H24 (C18, C22, C23); 2: H4 (C1, C2, C3, C6), H8 (C6, C10, C12), H9 (C7, C11), H10 (C11, C12), H14 (C6, C12, C13, C16), H20 (C18, C22), H22 (C18, C20, C24), H24 (C18, C22, C23); 10: H2 (C1, C3, C4, C16), H4 (C2, C5, C6, C14), H8 (C6, C10), H9 (C7, C11), H10 (C8, C12), H20 (C18, C19, C21, C22, C23), H21 (C19, C20, C22, C23), H22 (C20, C21, C23), H23 (C21, C22, C23); 12: H2 (C1, C3, C4, C16), H4 (C2, C5, C6, C14), H8 (C6, C10), H9 (C7, C11), H10 (C8, C12), H20 (C17, C18, C19, C22), H21 (C19, C20, C22, C23), H22 (C20, C21, C23), H23 (C21, C22, C23), H25 (C1). LR-ESIMS and HR-ESIMS were collected under positive or negative ionization mode as follows: (+)-ESI mass spectra are obtained as $[\mathrm{M}+\mathrm{H}]^{+}$or $[\mathrm{M}+\mathrm{Na}]^{+}$and all (-)-ESI mass spectra are obtained as [M-H] $]^{-}$. LR-ESIMS m/z: 1: $451.2\left([\mathrm{M}-\mathrm{H}]^{-}\right.$, $\left.\mathrm{C}_{24} \mathrm{H}_{19} \mathrm{O}_{9}\right) ; 2: 433.0\left([\mathrm{M}-\mathrm{H}]^{-}, \mathrm{C}_{24} \mathrm{H}_{17} \mathrm{O}_{8}\right) ; 3: 426.9\left([\mathrm{M}+\mathrm{H}]^{+}, \mathrm{C}_{23} \mathrm{H}_{23} \mathrm{O}_{8}\right) ; 4: 440.9$ ([M $+\mathrm{H}]^{+}, \mathrm{C}_{24} \mathrm{H}_{25} \mathrm{O}_{8}$ ). HR-ESIMS m/z: 5: 427.1389 (calculated for $\mathrm{C}_{23} \mathrm{H}_{23} \mathrm{O}_{8}: 427.1393$ ); 6 : 441.1549 (calculated for $\mathrm{C}_{24} \mathrm{H}_{25} \mathrm{O}_{8}: 441.1549$ ); 7: 409.1293 (calculated for $\mathrm{C}_{23} \mathrm{H}_{21} \mathrm{O}_{7}$ : 409.1287); 8: 423.1442 (calculated for $\mathrm{C}_{24} \mathrm{H}_{23} \mathrm{O}_{7}: 423.1444$ ); 9: 419.1125 (calculated for $\mathrm{C}_{22} \mathrm{H}_{20} \mathrm{O}_{7} \mathrm{Na}$ : 419.1107); 10: 461.1225 (calculated for $\mathrm{C}_{24} \mathrm{H}_{22} \mathrm{O}_{8} \mathrm{Na}: 461.1212$ ); 11: 433.1255 (calculated for $\mathrm{C}_{23} \mathrm{H}_{22} \mathrm{O}_{7} \mathrm{Na}$ : 433.1263); 12: 475.1364 (calculated for $\mathrm{C}_{25} \mathrm{H}_{24} \mathrm{O}_{8} \mathrm{Na}$ : 
475.1369). HR-ESIMS was performed at the Vincent Coates Foundation Mass Spectrometry Laboratory at Stanford University using a Micromass QTof API US (Manchester, United Kingdom) quadrupole-time of flight mass spectrometer, which was operated in MS-only mode with an internal standard (poly-alanine, Sigma P9003).

\section{Results}

The plasmids constructed for this study are shown in Table 1 . The plasmids were derived from the E. coli/S. coelicolor shuttle vector pRM5. ${ }^{16}$ (Figure 1 in Supporting Information) Each of the plasmids was transformed into the engineered S. coelicolor host CH999 16 and the production of polyketides was initially assayed by using LC-MS.

\section{Evaluation of KS-CLF enzymes from spore pigment biosynthetic pathways as catalysts for novel decaketide biosynthesis}

For the biosynthesis of new aklanonic acid derivatives, we first examined the ability of dodecaketide-specific Sch KS-CLF from the spore pigment biosynthetic pathway of $S$. halstedii 26 to productively interact with the R1128 initiation PKS module. The biosynthetic products of both the Sch minimal PKS alone and the Sch minimal PKS with actIII KR have been characterized. ${ }^{30}$ (Figure 4, and Figure 2 in Supporting Information) When the Sch KSCLF was recombined with the WhiE ACP (pYT227), we were able to observe the unreduced dodecaketides (TW93c-d). Similarly, addition of KR to pYT227 (resulting in pYT226) gave rise to the reduced dodecaketides TW94c-d. The genes encoding the R1128 initiation module were therefore added to pYT227 and pYT226 to yield pYT232 and pYT231, respectively. Constructs pYT232 and pYT231 were introduced into S. coelicolor CH999 via transformation; however LC/MS analysis of their biosynthetic products did not reveal the presence of isobutyryl or propionyl primed polyketides, as observed earlier for minimal PKSs with shorter chain length specificity. ${ }^{24}$ Instead, the transformants only produced acetyl-primed products such as TW93c-d (CH999/pYT232) and TW94c-d (CH999/pYT231). Two new acetyl-primer derived biosynthetic products were isolated from CH999/pYT231, with masses of 452 and 434. The yields of these two compounds were comparable to TW94c-d. The two compounds were characterized using ${ }^{1} \mathrm{H}$ and ${ }^{13} \mathrm{C}$ NMR (Table 2) along with COSY and $\mathrm{HMBC}$ analysis. We anticipated that the compound with mass $434(\mathrm{YT} 231 \mathrm{~b}, 2)$ may be a dehydration product of the compound with mass 452 (YT231a, 1); this was confirmed by ${ }^{1} \mathrm{H}$ NMR spectroscopic analysis which shows that the two pairs of $d d$ peaks of H-8 and H-10 in the latter compound were replaced by aromatic proton peaks in the former. The two compounds were eventually characterized as having distinct cyclization patterns compared to TW94d (Figure 4 and Table 2).

We further examined the biosynthetic capacity of Sch KS-CLF by addition of the WhiE cyclase to pYT232 (resulting in pYT236). As we expected from the previous study by Moore et al.

30 , this construct resulted in abundant production of TW95a and TW95b (the isolated yields were $50 \mathrm{mg} / \mathrm{L}$ and $8 \mathrm{mg} / \mathrm{L}$, respectively), but it still did not produce any non-acetyl primed polyketide.

To attempt improving crosstalk between the R1128 initiation module and the Sch KS-CLF, we replaced the WhiE ACP with ZhuN, the ACP from the elongation module of the R1128 PKS. ${ }^{24}$ This modified bimodular PKS was constructed in the absence (pYT210) and presence (pYT209) of the ketoreductase gene. However, neither construct yielded any polyketide, not even the dodecaketides observed with CH999/pYT231 and CH999/pYT232. Thus there appears to be a fundamental incompatibility between initiation PKS modules from antibiotic pathways and elongation PKS modules from spore pigment pathways. 


\section{Biosynthesis of non-acetyl primed decaketide backbones using the pradimicin KS-CLF}

To find a dodecaketide synthase that could communicate successfully with R1128 initiation module, we selected the antifungal pradimicin polyketide synthase (pms) as a possible partner for the R1128 initiation module. The pms KS and CLF genes were amplified from genomic DNA of Actinomadura hibisca P157-2 by PCR. ${ }^{28}$ We replaced $t c m$ KS and tcm CLF cassettes in pYT128 with the $1.3 \mathrm{~kb}$ PacI-NsiI cassette of pms KS and $1.3 \mathrm{~kb}$ NsiI-XbaI cassette of pms CLF to yield pYT243 (Table 1). This construct was introduced into S. coelicolor CH999 by PEG-mediated transformation. LC/MS analysis of the crude extract from the resulting transformant showed two peaks with strong absorption at $280 \mathrm{~nm}$ and masses of 426 and 440, corresponding to the expected masses of SEK15-analogs primed by propionyl and isobutyryl groups, respectively (Scheme 1). The more abundant isobutyryl-primed compound was purified by preparative HPLC and TLC. ${ }^{1} \mathrm{H}$ NMR analysis of this compound showed similar peak assignments for most backbone protons to SEK15 ${ }^{34}$. (Table 3) This compound, however, had 3 more sets of peaks in aliphatic proton region than SEK15 had, and the most characteristic peak was a doublet with 6 protons at $\delta=0.8 \mathrm{ppm}$ which corresponds to two terminal methyl groups in isobutyryl primed compound. Further spectroscopic analysis with ${ }^{13} \mathrm{C}$ NMR and COSY confirmed the structure of this compound as the expected SEK15-analog (YT243b, 4) along with the comparison with spectroscopic data for SEK $15^{34}$.

To produce decaketide analogs reduced at C-9, we inserted the act KR gene into pYT243, yielding pYT266 (Table 1). The expected biosynthetic products were the propionyl- and isobutyryl-primed analogs of RM20b/c 35 (Scheme 1). Indeed, LC/MS analysis revealed two peaks with the expected masses of propionyl (YT266a, 5) and isobutyryl (YT266b, 6) primed RM20b (m/z $=427$ and 441 by (-)-ESIMS, respectively), both of which were confirmed by HR-ESIMS. The above results demonstrated that the compatible interactions between the R1128 initiation module and the elongation module from the pms PKS can indeed produce non-acetyl primed decaketides.

In a further step toward engineered biosynthesis of aklanonic acid analogs, we inserted the gene encoding the pradimicin cyclase into plasmids carrying the R1128 initiation module, the act KR, pms KS-CLF and either $z h u N$ or pms ACP, yielding plasmids pYT253 and pYT259, respectively. However, neither construct produced the expected C-7/C-12 cyclized polyketide. Instead, these constructs produced only the acetyl-primed compounds TW95a and TW95b, as evidenced by LC/MS analysis (data not shown). This result suggests that Pms CYC is a C-9 unreduced polyketide-specific cyclase like ZhuI and ZhuJ in R1128 PKS 24 and the cyclases in WhiE PKS ${ }^{30}$. We could not observe YT266 compounds peaks in LC/MS analysis and this suggests that Pms CYC works faster than act KR. We therefore replaced the pms CYC with another bifunctional aromatase/cyclase, the gris $\mathrm{ARO} / \mathrm{CYC}$ from the griseusin gene cluster, which has been previously used for synthesizing SEK $43^{36}$. The resulting construct (pYT292) was transformed into $S$. coelicolor $\mathrm{CH} 999$. The recombinant strain appeared to produce both the propionyl (YT292a, 7) and the isobutyryl (YT292b, 8) primed analogs of SEK43, as confirmed by LC/MS ( $\mathrm{m} / \mathrm{z}=411$ and 425, respectively, by (+)-ESIMS; 409 and 423 , respectively, by (-)-ESIMS) with a combined yield over $30 \mathrm{mg} / \mathrm{L}$. (Figure 4 ) The compound with $\mathrm{m} / \mathrm{z}=425$ from LC/MS, which was more abundant, was purified by successive purification steps and identified as the expected isobutyryl primed SEK43 (YT292b, 8) by ${ }^{1} \mathrm{H}$ and ${ }^{13} \mathrm{C}$ NMR, (Table 3) COSY, and comparison with SEK43. ${ }^{17}$ These results provide a basis for attempting the engineered biosynthesis of new aklanonic acid analogs.

\section{Biosynthesis of aklanonic acid analogs}

For the synthesis of aklanonic acid analogs with non-acetyl primer units, the monocyclic polyketide precursors of YT292a and YT292b must be cyclized in a controlled fashion into a tricyclic anthraquinone. For this we selected the dpsY cyclase from the daunorubicin 
biosynthetic pathway, ${ }^{12,37}$ The 820bp $d p s Y$ gene was amplified from genomic DNA of $S$. peucetius by PCR, and inserted as an SpeI-AvrII cassette into pYT292 to yield the construct pYT296. Based on earlier precedents, we anticipated that an endogenous oxygenase in $S$. coelicolor $\mathrm{CH} 999$ would be able to oxidize the tricyclic core into anthracyclic aklanonic acid analogs. ${ }^{17,24}$ The HPLC trace of the crude extract of CH999/pYT296 showed several characteristic anthraquinone-type peaks with absorption at $280 \mathrm{~nm}$ and $410 \mathrm{~nm}$. LC/MS analysis demonstrated that the two most abundant anthraquinone-type peaks have masses of 396 and 438, corresponding to the expected isobutyryl-primed aklanonic acid analog and perhaps a related compound that lacks one acetyl elongation unit. (Figure 3 in Supporting Information) Production of these metabolites was scaled up. Preparative TLC yielded three major yellow products when developed with $25 \%$ ethyl acetate in hexane plus $1 \%$ acetic acid. ${ }^{1} \mathrm{H}$ NMR analysis of one of the products revealed peaks to the aromatic hydrogen atoms and the $\mathrm{C}-2$ benzylic hydrogen of aklanonic acid, but this compound lacked the enolizable methylene in the aklanonic acid side chain $(\delta=6.0 \mathrm{ppm}$ ). (Table 4) MS analysis of this compound was also consistent with its identity as an isobutyryl primed nonaketide. Further spectroscopic analysis of the compound via ${ }^{13} \mathrm{C}$ NMR, COSY, and HMBC confirmed its structure as shown in Scheme 2 (YT296a, 9, $2 \mathrm{mg} / \mathrm{L}$ ). The ${ }^{1} \mathrm{H}$ and ${ }^{13} \mathrm{C}$ NMR spectra of the second compound suggested it was more closely related to aklanonic acid ${ }^{38}$, with additional peaks corresponding to the alkyl side chain, including a doublet corresponding to terminal methyl groups, analogous to YT243b (4) and YT292b (8). COSY and HMBC analyses confirmed the incorporation of isobutyryl primer into this polyketide backbone, and the compound was identified as the isobutyryl primed decaketide (YT296b, 10,3 mg/L), expected analog of aklanonic acid. (Scheme 1) These findings demonstrate the feasibility of engineered biosynthesis of aklanonic acid analogs by harnessing the initiation module from the R1128 PKS, the elongation module from the pradimicin PKS, the act ketoreductase, the bifunctional gris aromatase/cyclase, and the DpsY cyclase from the daunorubicin biosynthetic pathway.

\section{Biosynthesis of aklanonic acid methyl ester analogs}

In daunorubicin biosynthesis (and presumably in the biosynthesis of other anthracyclines as well), the carboxylic acid of aklanonic acid is converted into a methyl ester, presumably by the DnrC protein. ${ }^{33}$ Therefore, we cloned the $850 \mathrm{bp} \operatorname{dnrC}$ gene from genomic DNA of $S$. peucetius by PCR, and inserted the corresponding SpeI-AvrII cassette into pYT296, yielding pYT299. The recombinant $S$. coelicolor strain CH999/pYT299 was found to produce anthraquinone-like compounds, with expectedly longer retention times via reverse phase HPLC. LC/MS analysis of crude extracts from this culture identified the two most abundant anthraquinone-type products as compounds with masses 410 and 452. Corresponding [M $-\mathrm{OMe}]^{+}$peaks (379 and 421 , respectively) were also observed, suggesting that these compounds were the isobutyryl-primed nonaketide and decaketide anthraquinones, respectively. Large scale production led to their isolation and identification as methyl esters of YT296a (YT299a, 11, $2 \mathrm{mg} / \mathrm{L}$ ) and YT296b (YT299b, 12, $1 \mathrm{mg} / \mathrm{L}$ ) by spectroscopic comparison with authentic aklanonic acid methyl ester. ${ }^{38}$

\section{Discussion}

Polyketides are a pharmacologically important class of natural products, having yielded many clinically useful drugs. A number of improved analogs of therapeutically promising polyketides have been prepared by synthetic and, more recently, biosynthetic means. In particular, engineering biosynthetic pathways of polyketide antibiotics to incorporate novel primer units is an effective way to generate analogs of existing natural products. $15,39,24$

In recent reports, we and others have shown that bacterial aromatic PKSs can be engineered to synthesize rationally modified polycyclic aromatic polyketides. ${ }^{24,40,41,42}$ Specifically, we 
have harnessed bimodular PKSs to produce engineered hexaketides and octaketides. ${ }^{24}$ Since some of the most pharmacologically interesting polyketides, including important anticancer drugs such as doxorubicin and aclacinomycin, are decaketides, we wished to extend our methodology for primer unit modification to decaketide natural products. In doing so, however, our attempt to harness the dodecaketide PKS from spore pigment pathways failed. Analysis of this failure has highlighted the possible existence of a fundamental incompatibility between initiation modules from antibiotic pathways and elongation modules from spore pigment pathways. Fortunately, the dodecaketide synthase from the pradimicin pathway was able to productively interact with the R1128 initiation module to produce non-acetyl primed decaketides, including novel aklanonic acid analogs. Aklanonic acid is a key biosynthetic intermediate in the formation of several pharmacologically intriguing anthracyclines. The 4methylpentanoyl primed aklanonic acid analog (YT296b, 10) and its methyl ester (YT299b, 12) were biosynthesized by an engineered bimodular aromatic polyketide synthase, together with a nonaketide product (YT296a, 9) and its methyl ester (YT299a, 11).

As has been recently demonstrated, the biosynthetic potential of this new source of anthracycline antibiotics can be considerably expanded by feeding natural and unnatural amino acids to the producer organisms. ${ }^{43}$ For example, we recently produced the 2-cyclopropylacetyl primed aromatic octaketide, 3,8-dihydroxy-1-(3-cyclopropylpropyl)-anthraquinone-2carboxylic acid, from a culture of CH999/pYT12724 by feeding $1 \mathrm{~g} / \mathrm{L}$ of cyclopropyl alanine to this organism. The amino acid is converted into 2-cyclopropylacetyl-CoA through amino acid catabolism, which in turn is incorporated into the polyketide backbone. ${ }^{44}$ The cyclopropyl functionality is useful for a variety of synthetic modifications, highlighting the potential for chemo-biosynthetic expansion of the aglycone library. 45

Further biosynthetic elaboration of these new aklanonic acid analogs can be achieved by reconstituting in S. coelicolor $\mathrm{CH} 999$ a variety of downstream enzymes such as the fourth ring cyclase $(\mathrm{dnrD})$, the ketoreductase $(\mathrm{dnrE})$, and the glycosyltransferases from the daunorubicin pathway (Figure 2). ${ }^{33,46,47}$ Analogous glycosyltransferases have been identified in the daunorubicin 48 and aclacinomycin $\mathrm{A}^{49}$ biosynthetic gene clusters. Although the tolerance of these tailoring enzymes for our new aklanonic acid analogs remains to be established, recent studies suggest that the ${ }_{\mathrm{L}}$-2-deoxyfucosyltransferase (AknK) from the aclacinomycin A pathway has broad substrate specificity. ${ }^{49}$

In conclusion, engineering of bimodular aromatic polyketide synthases has opened the door to qualitatively novel anthracycline antibiotics through modifications at a position not readily accessible by synthetic methods alone.

\section{Acknowledgements}

We thank Dr. Allis Chien at the Stanford Mass Spectrometry Facility and Dr. Stephen Lynch at the Stanford Chemistry Department NMR Facility for providing helps with the mass spectrometric and the NMR spectroscopic analysis of the compounds. This work was supported by a grant from the National Institutes of Health (NIH) (CA 77248 to CK).

\section{References}

1. O'Hagan, D., The Polyketide Metabolites. Chichester, UK, 1991

2. Hopwood DA. Chem Rev 1997;97:2465. [PubMed: 11851466]

3. Binaschi M, Bigioni M, Cipollone A, Rossi C, Goso C, Maggi CA, Capranico G, Animati F. Curr Med Chem-Anti-Cancer Agents 2001;1:113.

4. Arcamone F, Cassinelli G. Curr Med Chem 1998;5:391. [PubMed: 9756981]

5. Arcamone FM. Biochimie 1998;80:201. [PubMed: 9615860]

6. Grandi M, Pezzoni G, Ballinari D, Capolongo L, Suarato A, Bargiotti A, Faiardi D, Spreafico F. Cancer Treat Rev 1990;17:133. [PubMed: 2272029] 
7. Capranico G, Supino R, Binaschi M, Capolongo L, Grandi M, Suarato A, Zunino F. Mol Pharmacol 1994;45:908. [PubMed: 8190107]

8. Capranico G, Zunino F, Kohn KW, Pommier Y. Biochemistry 1990;29:562. [PubMed: 2154250]

9. Bachur NR. J Pharmacol Exp Ther 1971;177:573. [PubMed: 5568811]

10. Cassinelli G, Grein A, Masi P, Suarato A, Bernardi L, Arcamone F, Di Marco A, Casazza AM, Pratesi G, Soranzo C. J Antibiot 1978;31:178. [PubMed: 649513]

11. Acton EM, Tong GL, Mosher CW, Smith TH, Henry DW. J Med Chem 1979;22:922. [PubMed: 490537]

12. Hutchinson CR. Chem Rev 1997;97:2525. [PubMed: 11851469]

13. Kantola J, Kunnari T, Hautala A, Hakala J, Ylihonko K, Mantsala P. Microbiology 2000;146(Pt 1): 155. [PubMed: 10658662]

14. Madduri K, Kennedy J, Rivola G, Inventi-Solari A, Filippini S, Zanuso G, Colombo AL, Gewain KM, Occi JL, MacNeil DJ, Hutchinson CR. Nat Biotechnol 1998;16:69. [PubMed: 9447597]

15. Moore BS, Hertweck C. Nat Prod Rep 2002;19:70. [PubMed: 11902441]

16. McDaniel R, Ebert-Khosla S, Hopwood DA, Khosla C. Science 1993;262:1546. [PubMed: 8248802]

17. McDaniel R, Ebert-Khosla S, Hopwood DA, Khosla C. Nature 1995;375:549. [PubMed: 7791871]

18. Hopwood DA, Sherman DH. Annu Rev Genet 1990;24:37. [PubMed: 2088174]

19. Hori Y, Abe Y, Ezaki M, Goto T, Okuhara M, Kohsaka M. J Antibiot 1993;46:1055. [PubMed: 8360099]

20. Sitachitta N, Gadepalli M, Davison BS. Tetrahedron 1996;52:8073.

21. Piel J, Hertweck C, Shipley PR, Hunt DM, Newman MS, Moore BS. Chem Biol 2000;7:943. [PubMed: 11137817]

22. Meadows ES, Khosla C. Biochemistry 2001;40:14855. [PubMed: 11732905]

23. Bao W, Sheldon PJ, Wendt-Pienkowski E, Hutchinson CR. J Bacteriol 1999;181:4690. [PubMed: 10419974]

24. Tang Y, Lee TS, Khosla C. PLoS Biol 2004;2:E31. [PubMed: 14966533]

25. Davis NK, Chater KF. Mol Microbiol 1990;4:1679. [PubMed: 2077356]

26. Blanco G, Pereda A, Mendez C, Salas JA. Gene 1992;112:59. [PubMed: 1551599]

27. Bergh S, Uhlen M. Gene 1992;117:131. [PubMed: 1644304]

28. Dairi T, Hamano Y, Igarashi Y, Furumai T, Oki T. Biosci Biotechnol Biochem 1997;61:1445. [PubMed: 9339544]

29. Kieser, T.; Bibb, M. J.; Buttner, M. J.; Charter, K. F.; Hopwood, D. A., Practical Streptomyces Genetics. The John Innes Foundation: Norwich, 2000

30. Yu TW, Shen Y, McDaniel R, Floss HG, Khosla C, Hopwood DA, Moore BS. J Am Chem Soc 1998;120:7749.

31. Yu TW, Bibb MJ, Revill WP, Hopwood DA. J Bacteriol 1994;176:2627. [PubMed: 8169211]

32. Lomovskaya N, Doi-Katayama Y, Filippini S, Nastro C, Fonstein L, Gallo M, Colombo AL, Hutchinson CR. J Bacteriol 1998;180:2379. [PubMed: 9573189]

33. Madduri K, Hutchinson CR. J Bacteriol 1995;177:3879. [PubMed: 7601857]

34. Fu H, Ebert-Khosla S, Hopwood D, Khosla C. J Am Chem Soc 1994;116:4166.

35. Fu H, McDaniel R, Hopwood DA, Khosla C. Biochemistry 1994;33:9321. [PubMed: 8049233]

36. Zawada RJ, Khosla C. J Biol Chem 1997;272:16184. [PubMed: 9195917]

37. Hautala A, Torkkell S, Raty K, Kunnari T, Kantola J, Mantsala P, Hakala J, Ylihonko K. J Antibiot 2003;56:143. [PubMed: 12715874]

38. Eckardt K, Tresselt D, Schumann G, Ihn W, Wagner C. J Antibiot 1985;38:1034. [PubMed: 3862658]

39. Denoya CD, Fedechko RW, Hafner EW, McArthur HA, Morgenstern MR, Skinner DD, StutzmanEngwall K, Wax RG, Wernau WC. J Bacteriol 1995;177:3504. [PubMed: 7768860]

40. Hutchinson CR, Colombo AL. J Ind Microbiol Biotechnol 1999;23:647. [PubMed: 10455495]

41. Metsa-Ketela M, Palmu K, Kunnari T, Ylihonko K, Mantsala P. Antimicrob Agents Chemother 2003;47:1291. [PubMed: 12654660] 
42. Shen Y, Yoon P, Yu TW, Floss HG, Hopwood D, Moore BS. Proc Natl Acad Sci U S A 1999;96:3622. [PubMed: 10097087]

43. Tang Y, Lee TS, Lee HY, Khosla C. Tetrahedron 2004;60:7659.

44. The manuscript is prepared.

45. Wessjohann LA, Brandt W. Chem Rev 2003;103:1625. [PubMed: 12683792]

46. Dickens ML, Ye J, Strohl WR. J Bacteriol 1995;177:536. [PubMed: 7836284]

47. Kendrew SG, Katayama K, Deutsch E, Madduri K, Hutchinson CR. Biochemistry 1999;38:4794. [PubMed: 10200167]

48. Otten SL, Liu X, Ferguson J, Hutchinson CR. J Bacteriol 1995;177:6688. [PubMed: 7592454]

49. Lu W, Leimkuhler C, Oberthur M, Kahne D, Walsh CT. Biochemistry 2004;43:4548. [PubMed: 15078101] 


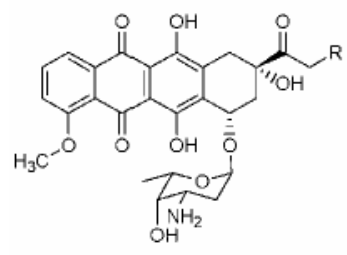

Daunonbicin $\mathrm{R}=\mathrm{H}$ Doxorubicin $\mathrm{R}=\mathrm{OH}$

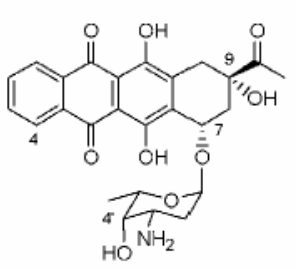

Idarubicin

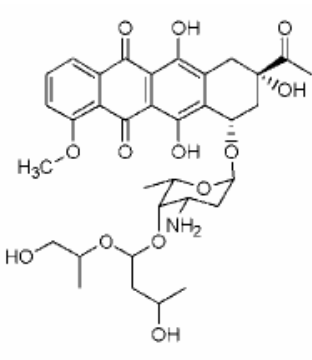

Baumycin Al<smiles>C=C1c2c(C)cccc2C(=O)c2cc3c(c(C)c21)C(C(C)=O)C[C@@](O)(CC)C3(C)C</smiles>

$\mathrm{OH}$ $\mathrm{Zr} 07$
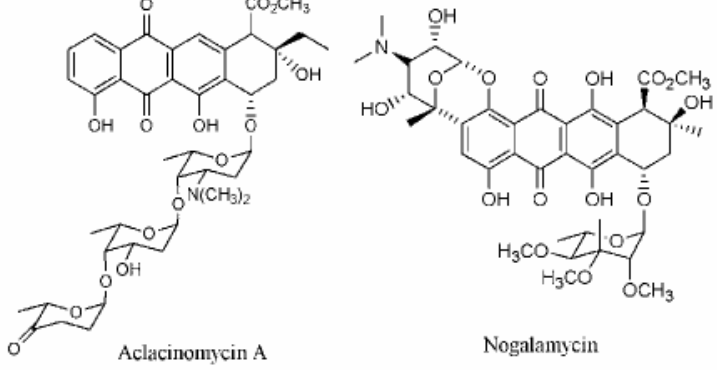

Nogalamycin

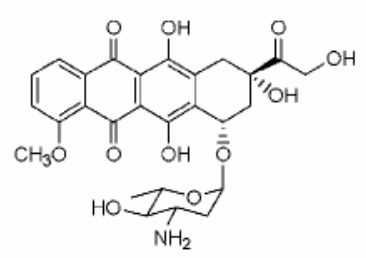

Epirubicin
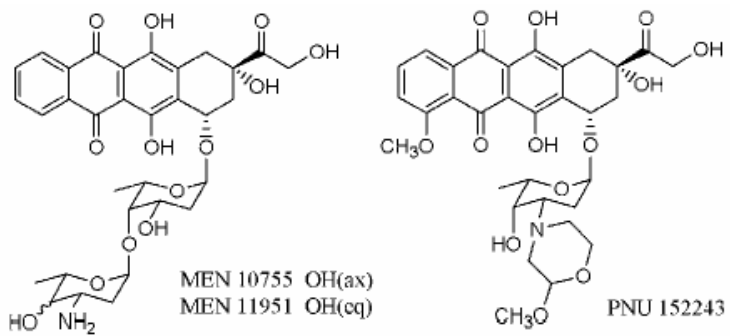

Figure 1.

(A) Examples of natural anthracycline polyketides

(B) Examples of clinically useful semisynthetic analogs of daunorubicin and doxorubicin. 


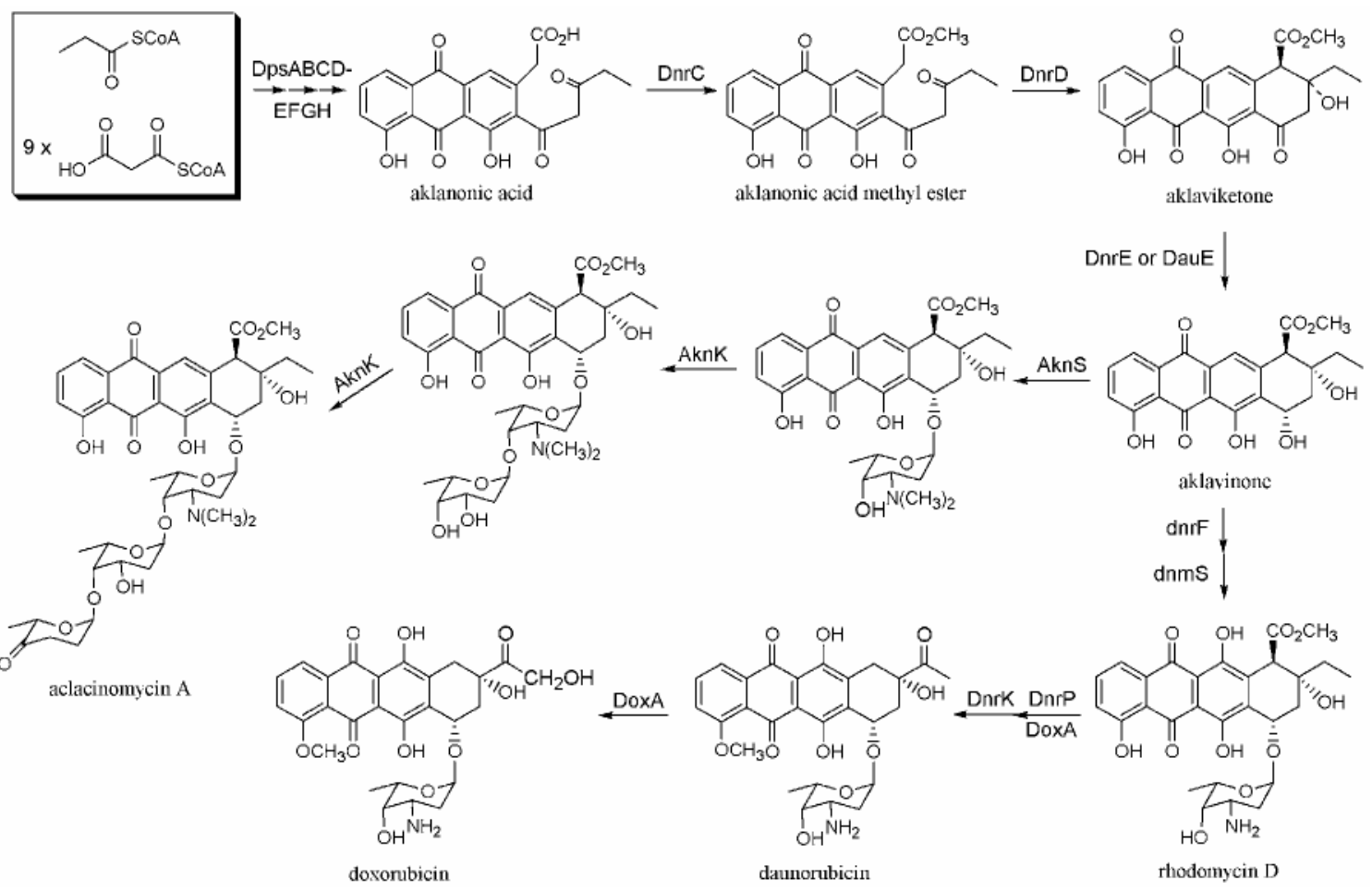

Figure 2.

Biosynthesis of daunorubicin, doxorubicin, and aclacinomycin A 
(A) Initiation Module

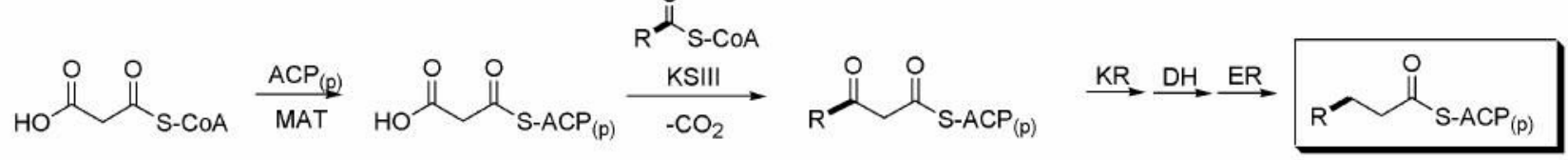

Elongation Module
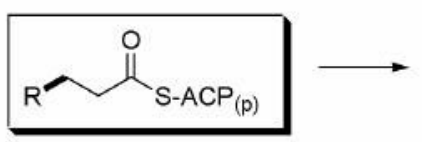<smiles>[R]CCC(=O)SNS(F)(F)F</smiles>

$7 x$

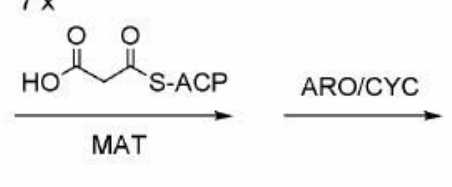

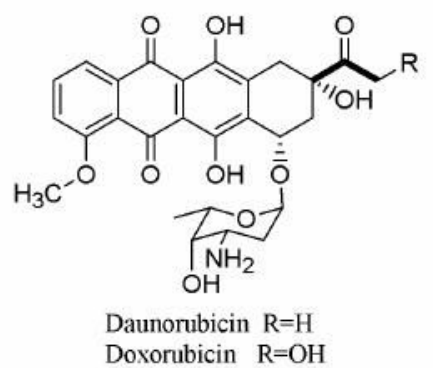

(B)

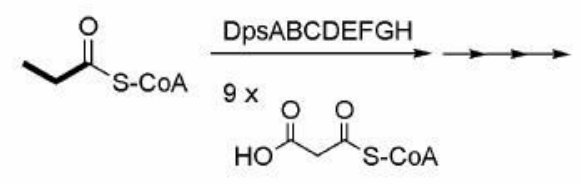

(C)

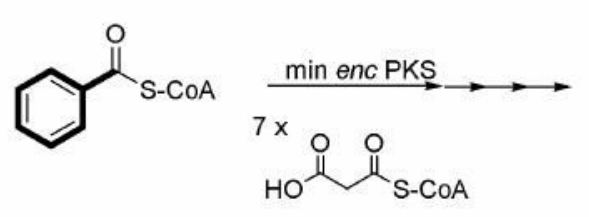<smiles>COc1cc(C[C@]2(O)C[C@H](O)CC(=O)[C@@]2(O)CC(=O)c2ccccc2)oc(=O)c1</smiles>

Wailupemycin A<smiles>O=C1C[C@@](O)(c2ccccc2)[C@@H](c2cc(O)cc(=O)o2)c2cccc(O)c21</smiles>

Wailupemycin D<smiles>[R]CCc1cc(O)cc2c1C(=O)c1c(O)cc(O)cc1C2=O</smiles>

$\mathrm{R} 1128 \mathrm{a}: \mathrm{R}=\mathrm{Me}$

$\mathrm{R} 1128 \mathrm{~b}: \mathrm{R}=\mathrm{Et}$

$\mathrm{R} 1128 \mathrm{c}: \mathrm{R}=\mathrm{iPr}$

R1128d : $\mathrm{R}=\mathrm{Pr}$

Figure 3.

Non-acetate primed polyketide biosynthesis. (A) R1128 biosynthesis (B) doxorubicin biosynthesis $(\mathrm{C})$ wailupemycin A biosynthesis. Primer units are in bold. 

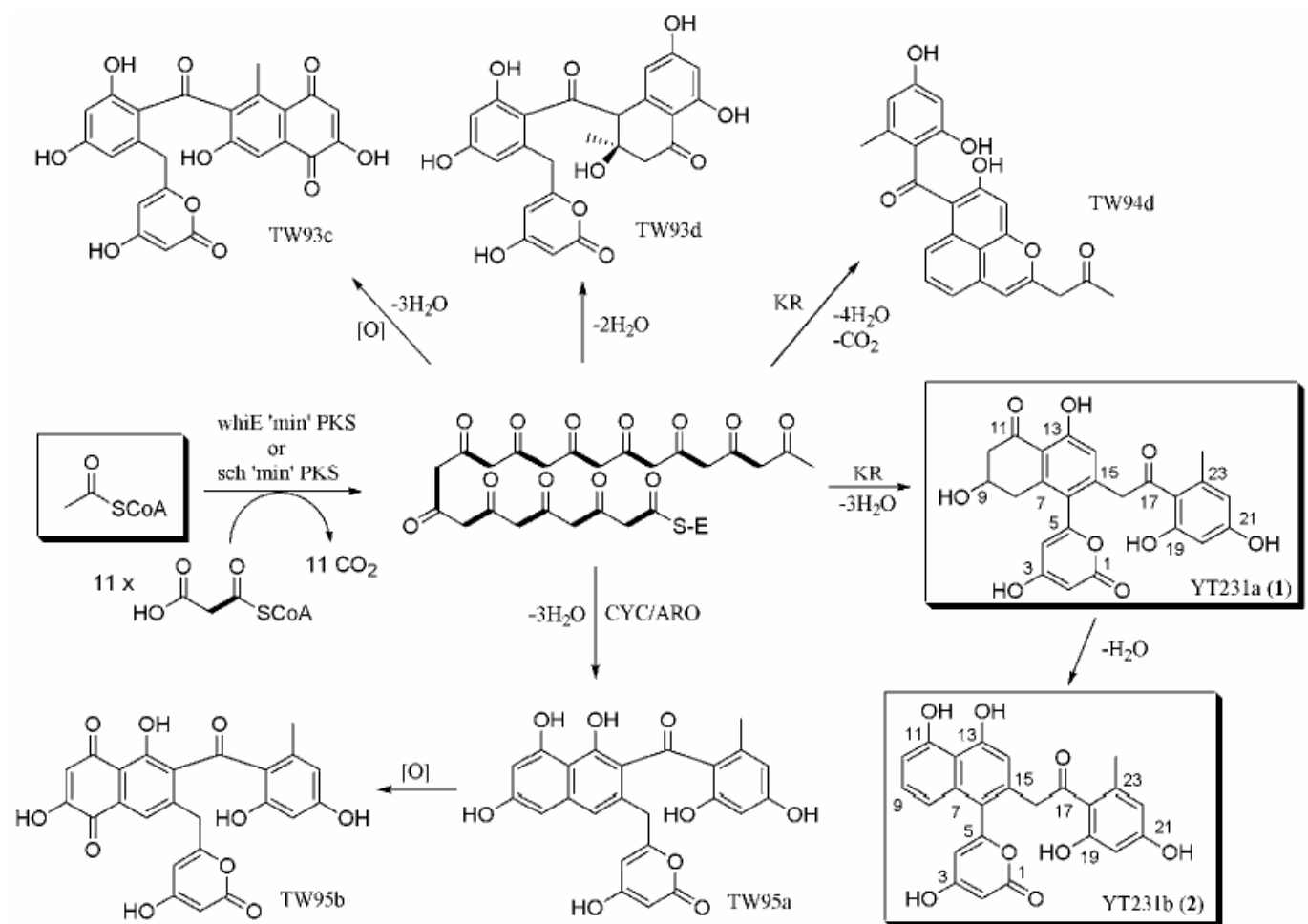

Figure 4.

Biosynthesis by spore pigment producing dodecaketide synthases 


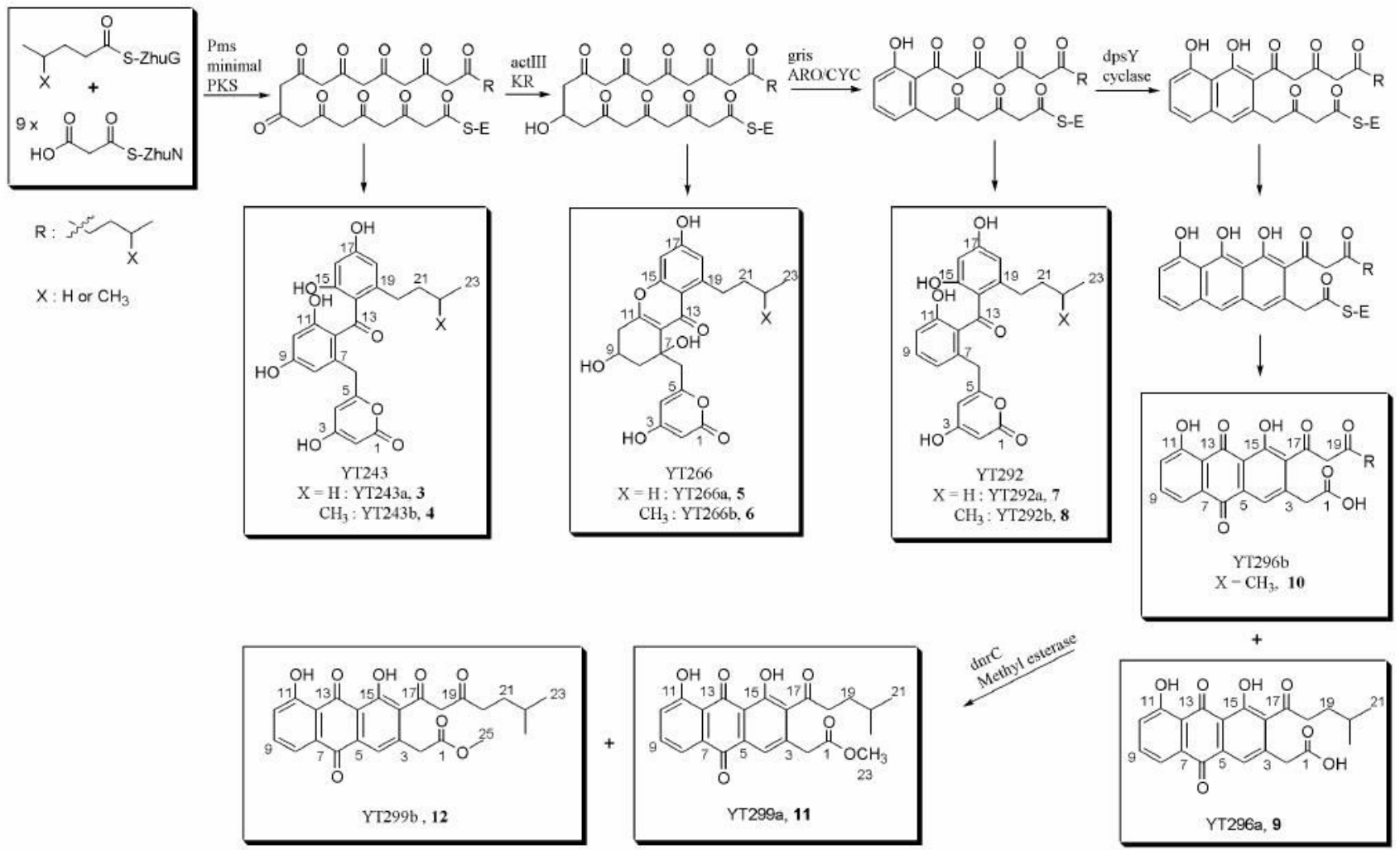

Scheme 1.

Biosynthesis of non-acetate primed decaketides by the bimodular dodecaketide polyketide synthases. 


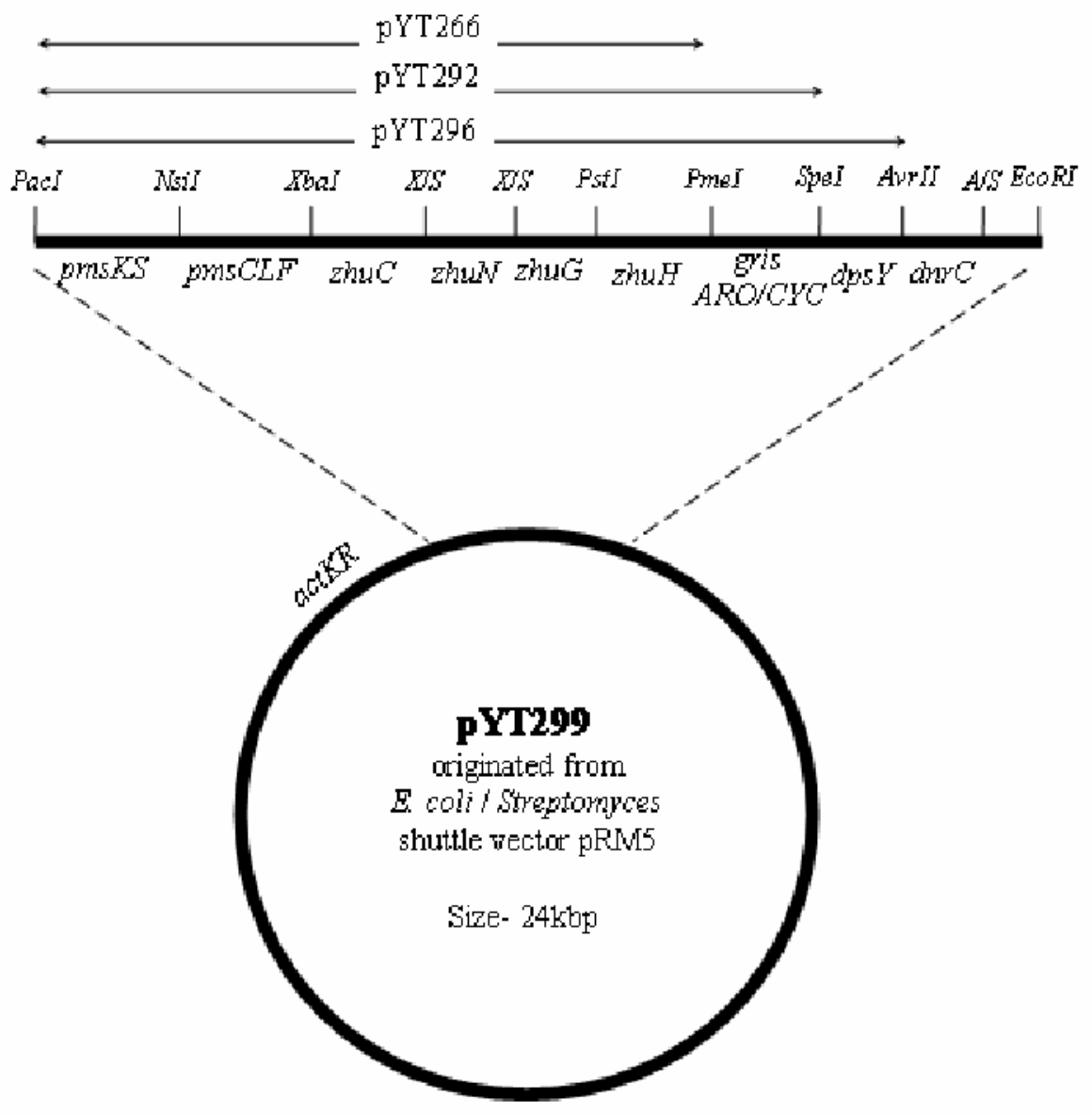

Supporting Information Figure 1.

Physical map of pYT299. The recombinant gene cassettes present in pYT266, pYT292 and pYT296 are also indicated. All biosynthetic operons have PacI and EcoRI restriction sites at their ends. X/S is made by ligating the compatible ends of $\mathrm{XbaI}$ and SpeI restriction sites. A/ $\mathrm{S}$ is made by ligating the compatible ends of AvrII and SpeI restriction sites. 


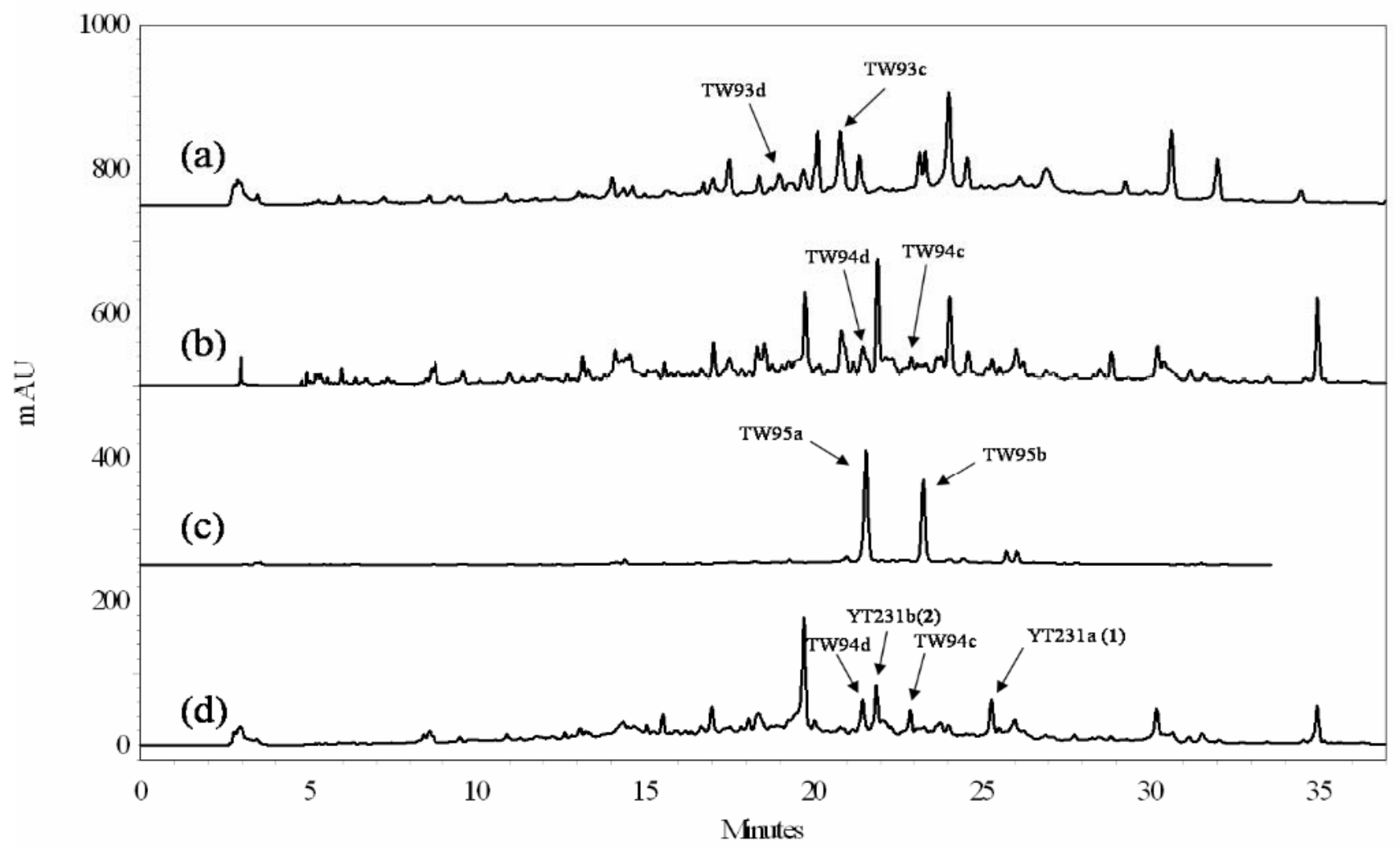

Supporting Information Figure 2.

HPLC trace of extracts from (a) CH999/YT227, (b) CH999/YT226, (c) CH999/YT236, and (d) $\mathrm{CH} 999 / \mathrm{YT} 231$. A linear gradient of $10 \%-60 \% \mathrm{CH}_{3} \mathrm{CN}$ in water was used and the trace was monitored by UV detector at $280 \mathrm{~nm}$. Peaks were assigned by LC/MS analysis. The indicated peaks were compared against authentic standards from extracts of the reported strains (Ref 30). The unassigned peaks were not further characterized, since they had a mass lower than 200 via LC/MS analysis. 


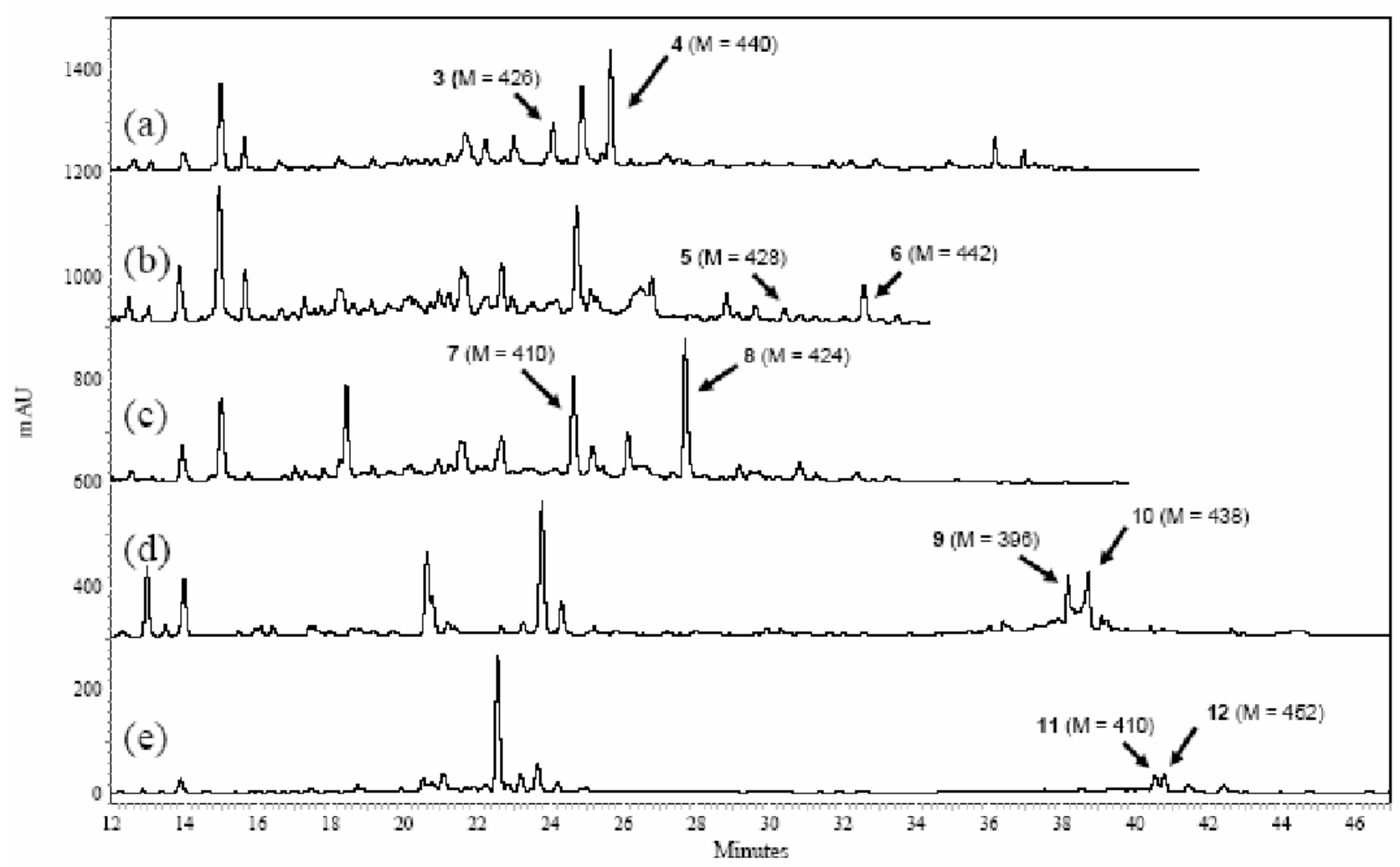

Supporting Information Figure 3.

HPLC trace of extracts from (a) CH999/YT243, (b) CH999/YT266, (c) CH999/YT292, (d)

CH999/YT296, and (e) CH999/YT299. A linear gradient of 10\%-60\% $\mathrm{CH}_{3} \mathrm{CN}$ in water was used and the trace was monitored by UV detector at $280 \mathrm{~nm}$. Peaks were assigned by LC/MS analysis and confirmed by NMR and/or HR-ESIMS analysis. None of major unassigned peaks show a mass higher than 200. In particular, the major peaks in (d) and (e) at 23.8 min and at $22.5 \mathrm{~min}$, respectively, were purified and analyzed. The peak at $23.8 \mathrm{~min}$ has a mass of 196, and the peak at 22.5 min shows a mass of 182. This, together with their ${ }^{1} \mathrm{H}$ NMR spectra (single aromatic peak), suggests that these compounds are either truncated polyketides (e.g., see ref. 30 ) or not polyketides at all. 
Table 1

Plasmids Constructions and Resulting Polyketide Products ${ }^{a}$

\begin{tabular}{|c|c|c|c|c|c|c|}
\hline Plasmid & Minimal PKS ${ }^{b}$ & $\underset{\text { (actIII) }}{\mathbf{K R}}$ & Aromatase, Cyclase & R1128 LM & Polyketide Products & Ref \\
\hline pYT227 & $\begin{array}{c}\text { sch with whiE } \\
A C P\end{array}$ & - & - & - & TW93c-h & Ref. 30 \\
\hline pYT226 & $\begin{array}{c}\text { sch with whiE } \\
A C P\end{array}$ & + & - & - & $\begin{array}{c}\text { TW94c-d YT231a, b } \\
(\mathbf{1}, \mathbf{2})\end{array}$ & $\begin{array}{l}\text { Ref. } 30 \\
\text { This work }\end{array}$ \\
\hline pYT232 & $\begin{array}{c}\text { sch with whiE } \\
A C P\end{array}$ & - & - & + & TW93c-h & This work \\
\hline pYT231 & $\begin{array}{c}\text { sch with whiE } \\
\text { ACP }\end{array}$ & + & - & + & $\begin{array}{c}\text { TW94c-d YT231a, b } \\
(\mathbf{1}, \mathbf{2})\end{array}$ & This work \\
\hline pYT236 & $\begin{array}{c}\text { sch with whiE } \\
\text { ACP }\end{array}$ & - & whiE CYC & + & TW95a, b & $\begin{array}{l}\text { Ref. } 30 \\
\text { This work }\end{array}$ \\
\hline pYT210 & sch with zhuN & - & zhuI, zhuJ & + & No polyketide & This work \\
\hline pYT209 & sch with zhuN & + & actVII, actIV & + & No polyketide & This work \\
\hline pYT243 & pms with zhuN & - & - & + & $\begin{array}{l}\text { YT243a, b }(\mathbf{3}, \mathbf{4}) \\
\text { (SEK15-like) }\end{array}$ & This work \\
\hline pYT266 & pms with zhuN & + & - & + & $\begin{array}{l}\text { YT266a, b (5, 6) } \\
\text { (RM20b-like) }\end{array}$ & This work \\
\hline pYT253 & pms with zhuN & + & pms $C Y C$ & + & TW95a, b & This work \\
\hline pYT259 & $\begin{array}{l}\text { pms with pms } \\
\text { ACP }\end{array}$ & + & pms CYC & + & TW95a, b & This work \\
\hline pYT292 & pms with zhuN & + & grisARO/CYC & + & $\begin{array}{c}\text { YT292a, b }(\mathbf{7}, \mathbf{8}) \\
\text { (SEK43-like) }\end{array}$ & This work \\
\hline pYT296 & pms with zhuN & + & grisARO/CYC dps $Y$ & + & $\begin{array}{c}\text { YT296a, b }(\mathbf{9}, \mathbf{1 0}) \\
\text { (aklanonic acid-like) }\end{array}$ & This work \\
\hline $\mathrm{p}_{c} \mathrm{YT} 299$ & pms with zhuN & + & grisARO/CYC dps $Y$ & + & $\begin{array}{l}\text { YT299a, b (11, 12) } \\
\text { (methyl ester) }\end{array}$ & This work \\
\hline
\end{tabular}

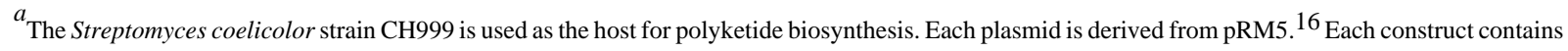
genes for the minimal PKS, cyclases and the R1128 initiation module, which consists of $z h u G$, $z h u H$ and $z h u C$. Products are analyzed by LC/MS and NMR.

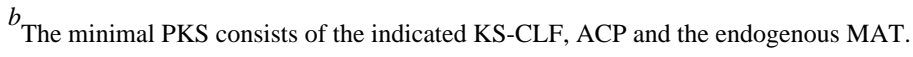

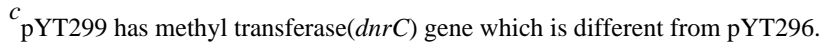


Table 2

${ }^{1} \mathrm{H}$ and ${ }^{13} \mathrm{C}$ NMR assignments for YT231a (1) and YT231b (2) ${ }^{a}$

\begin{tabular}{|c|c|c|c|c|}
\hline \multirow[b]{2}{*}{ No ${ }^{b}$} & \multicolumn{2}{|c|}{ YT231a } & \multicolumn{2}{|c|}{ YT231b } \\
\hline & ${ }^{13} \mathrm{C} \delta(\mathrm{ppm})$ & ${ }^{1} \mathbf{H} \delta(\mathrm{ppm})\left(\mathrm{m}\right.$, area, $\left.J_{\mathrm{HH}}(\mathrm{Hz})\right)$ & ${ }^{13} \mathrm{C} \delta(\mathrm{ppm})$ & $\begin{array}{c}{ }^{1} \mathrm{H} \delta(\mathrm{ppm})\left(\mathrm{m}, \text { area, } J_{\mathrm{HH}}\right. \\
(\mathrm{Hz}))\end{array}$ \\
\hline 1 & 164.3 & & 162.6 & \\
\hline 2 & 90 & $5.44(\mathrm{~d}, 1 \mathrm{H}, 3)$ & 96 & $5.46(\mathrm{~d}, 1 \mathrm{H}, 2)$ \\
\hline 3 & 172.8 & & 173.5 & \\
\hline 4 & 107.5 & $6.11(\mathrm{~s}, 1 \mathrm{H})$ & 108.0 & $6.09(\mathrm{~d}, 1 \mathrm{H}, 2)$ \\
\hline 5 & 160.5 & & 157.3 & \\
\hline 6 & 125.8 & & 122.8 & \\
\hline 7 & 141.1 & & 136.1 & \\
\hline 8 & 37 & $\begin{array}{l}3.09(\mathrm{dd}, 1 \mathrm{H}, 4,17) \\
2.86(\mathrm{dd}, 1 \mathrm{H}, 6,17)\end{array}$ & 117.4 & $7.05(\mathrm{dd}, 1 \mathrm{H}, 1,8)$ \\
\hline 9 & 66.6 & $4.32(\mathrm{~m}, 1 \mathrm{H})$ & 129.2 & $7.28(\mathrm{t}, 1 \mathrm{H}, 8)$ \\
\hline 10 & 30.8 & $\begin{array}{l}2.97(\mathrm{dd}, 1 \mathrm{H}, 4,17) \\
2.75(\mathrm{dd}, 1 \mathrm{H}, 6,17)\end{array}$ & 109.9 & $6.75(\mathrm{dd}, 1 \mathrm{H}, 1,8)$ \\
\hline 11 & 203.9 & & 155.8 & \\
\hline 12 & 116.7 & & 114.9 & \\
\hline 13 & 161.9 & & 159.9 & \\
\hline 14 & 119.2 & $6.80(\mathrm{~s}, 1 \mathrm{H})$ & 111.9 & $6.71(\mathrm{~s}, 1 \mathrm{H})$ \\
\hline 15 & 143.1 & & 141.7 & \\
\hline 16 & 47.3 & $4.25(\mathrm{~d}, 2 \mathrm{H}, 19)$ & 49.9 & $4.30(\mathrm{~s}, 2 \mathrm{H})$ \\
\hline 17 & 204.9 & & 205.4 & \\
\hline 18 & 120.0 & & 120.6 & \\
\hline 19 & 161.2 & & 161.5 & \\
\hline 20 & 101.4 & $6.14(\mathrm{~s}, 1 \mathrm{H})$ & 101.3 & $6.13(\mathrm{~d}, 1 \mathrm{H}, 2)$ \\
\hline 21 & 168.1 & & 168.9 & \\
\hline 22 & 111.1 & $6.14(\mathrm{~s}, 1 \mathrm{H})$ & 110.8 & $6.15(\mathrm{~d}, 1 \mathrm{H}, 2)$ \\
\hline 23 & 145.8 & & 140.5 & \\
\hline 24 & 21.4 & $2.16(\mathrm{~s}, 3 \mathrm{H})$ & 21.0 & $2.08(\mathrm{~s}, 3 \mathrm{H})$ \\
\hline
\end{tabular}

${ }^{a}$ Spectra were obtained at $500 \mathrm{MHz}$ for proton and $125 \mathrm{MHz}$ for carbon and were recorded in CD3OD.

${ }^{b}$ Carbons are labeled as shown in Figure 4. 
Table 3

${ }^{1} \mathrm{H}$ and ${ }^{13} \mathrm{C}$ NMR assignments for YT243b (4) and YT292b (8) ${ }^{a}$

\begin{tabular}{|c|c|c|c|c|}
\hline \multirow[b]{2}{*}{$\mathrm{No}^{b}$} & \multicolumn{2}{|c|}{ YT243b } & \multicolumn{2}{|r|}{ YT292b } \\
\hline & ${ }^{13} \mathrm{C} \delta(\mathrm{ppm})$ & $\begin{array}{c}{ }^{1} \mathrm{H} \delta(\mathrm{ppm})\left(\mathrm{m}, \operatorname{area} J_{\mathrm{HH}}\right. \\
(\mathrm{Hz}))\end{array}$ & ${ }^{13} \mathrm{C} \delta(\mathrm{ppm})$ & ${ }^{1} \mathbf{H} \delta(\mathrm{ppm})\left(\mathrm{m}\right.$, area, $\left.J_{\mathrm{HH}}(\mathrm{Hz})\right)$ \\
\hline 1 & 164.0 & & 166.8 & \\
\hline 2 & 86.6 & $4.90(\mathrm{~s}, 1 \mathrm{H})$ & 88.0 & $4.96(\mathrm{~s}, 1 \mathrm{H})$ \\
\hline 3 & 172.8 & & 172.3 & \\
\hline 4 & 101.8 & $5.49(\mathrm{~s}, 1 \mathrm{H})$ & 101.8 & $5.51(\mathrm{~s}, 1 \mathrm{H})$ \\
\hline 5 & 163.1 & & 162.3 & \\
\hline 6 & 39.0 & $3.53(\mathrm{~s}, 2 \mathrm{H})$ & 36.6 & $3.53(\mathrm{~s}, 2 \mathrm{H})$ \\
\hline 7 & 135.4 & & 133.6 & \\
\hline 8 & 109.1 & $6.27(\mathrm{~s}, 1 \mathrm{H})$ & 130.7 & $6.76(\mathrm{~d}, 1 \mathrm{H}, 8)$ \\
\hline 9 & 159.8 & & 120.8 & $7.18(\mathrm{t}, 1 \mathrm{H}, 8)$ \\
\hline 10 & 101.6 & $6.16(\mathrm{~s}, 1 \mathrm{H})$ & 114.7 & $6.72(\mathrm{~d}, 1 \mathrm{H}, 8)$ \\
\hline 11 & 157.4 & & 154.5 & \\
\hline 12 & 121.1 & & 130.0 & \\
\hline 13 & 200.1 & & 199.4 & \\
\hline 14 & 117.2 & & 116.8 & \\
\hline 15 & 163.6 & & 163.0 & \\
\hline 16 & 100.6 & $6.16(\mathrm{~s}, 1 \mathrm{H})$ & 100.4 & $6.09(\mathrm{~s}, 1 \mathrm{H})$ \\
\hline 17 & 162.2 & & 162.7 & \\
\hline 18 & 111.0 & $6.30(\mathrm{~s}, 1 \mathrm{H})$ & 109.3 & $6.11(\mathrm{~s}, 1 \mathrm{H})$ \\
\hline 19 & 141.9 & & 147.4 & \\
\hline 20 & 36.8 & $2.23(\mathrm{t}, 2 \mathrm{H}, 8)$ & 32.3 & $2.27(\mathrm{t}, 2 \mathrm{H}, 8)$ \\
\hline 21 & 27.7 & $1.37-1.32(\mathrm{~m}, 2 \mathrm{H})$ & 27.8 & $1.06-1.01(\mathrm{~m}, 2 \mathrm{H})$ \\
\hline 22 & 31.0 & $1.37-1.32(\mathrm{~m}, 1 \mathrm{H})$ & 39.4 & $1.28-1.24(\mathrm{~m}, 1 \mathrm{H})$ \\
\hline 23 & 22.2 & $0.78(\mathrm{~d}, 6 \mathrm{H}, 6.5)$ & 22.2 & $0.70(\mathrm{~d}, 6 \mathrm{H}, 6.5)$ \\
\hline
\end{tabular}

\footnotetext{
${ }^{a}$ Spectra were obtained at $500 \mathrm{MHz}$ for proton and $125 \mathrm{MHz}$ for carbon and were recorded in CD3OD.

${ }^{b}$ Carbons are labeled as shown in Scheme 1.
} 
Table 4

${ }^{1} \mathrm{H}$ and ${ }^{13} \mathrm{C}$ NMR assignments for YT296a, b (9, 10), YT299a, b (11, 12) ${ }^{a}$

\begin{tabular}{|c|c|c|c|c|c|c|c|c|}
\hline \multirow[b]{2}{*}{$\mathrm{No}^{b}$} & \multicolumn{2}{|c|}{ YT296a } & \multicolumn{2}{|c|}{ YT296b } & \multicolumn{2}{|c|}{ YT299a } & \multicolumn{2}{|c|}{ YT299b } \\
\hline & $\begin{array}{l}{ }^{13} \mathrm{C} \delta \\
(\mathrm{ppm})\end{array}$ & $\begin{array}{l}{ }^{1} \mathrm{H} \delta(\mathrm{ppm})(\mathrm{m}, \\
\left.\operatorname{area} J_{\mathrm{HH}}(\mathrm{Hz})\right)\end{array}$ & $\begin{array}{c}{ }^{13} \mathrm{C} \delta \\
(\mathrm{ppm})\end{array}$ & $\begin{array}{l}{ }^{1} \mathrm{H} \delta(\mathrm{ppm})(\mathrm{m}, \\
\left.\operatorname{area} J_{\mathrm{HH}}(\mathrm{Hz})\right)\end{array}$ & $\begin{array}{l}{ }^{13} \mathrm{C} \delta \\
(\mathrm{ppm})\end{array}$ & $\begin{array}{l}{ }^{1} \mathrm{H} \delta(\mathrm{ppm})(\mathrm{m}, \\
\left.\operatorname{area} J_{\mathrm{HH}}(\mathrm{Hz})\right)\end{array}$ & $\begin{array}{c}{ }^{13} \mathrm{C} \delta \\
(\mathrm{ppm})\end{array}$ & $\begin{array}{l}{ }^{1} \mathrm{H} \delta(\mathrm{ppm})(\mathrm{m}, \\
\left.\text { area } J_{\mathrm{HH}}(\mathrm{Hz})\right)\end{array}$ \\
\hline 1 & 172.4 & & 172.6 & & 170.3 & & 170.3 & \\
\hline 2 & 39.4 & $3.80(\mathrm{~s}, 2 \mathrm{H})$ & 40.7 & $3.86(\mathrm{~s}, 2 \mathrm{H})$ & 38.9 & $3.791(\mathrm{~s}, 2 \mathrm{H})$ & 39.5 & $3.86(\mathrm{~s}, 2 \mathrm{H})$ \\
\hline 3 & 141.1 & & 141.3 & & 141.5 & & 142.7 & \\
\hline 4 & 122.5 & $7.78(\mathrm{~s}, 1 \mathrm{H})$ & 122.3 & $7.85(\mathrm{~s}, 1 \mathrm{H})$ & 122.6 & $7.78(\mathrm{~s}, 1 \mathrm{H})$ & 122.4 & $7.77(\mathrm{~s}, 1 \mathrm{H})$ \\
\hline 5 & 133.9 & & 134.2 & & 133.5 & & 133.7 & \\
\hline 6 & 181.0 & & 179.6 & & 192.8 & & 181.2 & \\
\hline 7 & 133.3 & & 132.8 & & 133.4 & & 132.5 & \\
\hline 8 & 125.2 & $\begin{array}{c}7.86 \\
(\mathrm{dd}, 1 \mathrm{H}, 8,1.2)\end{array}$ & 120.6 & $\begin{array}{c}7.86 \\
(\mathrm{dd}, 1 \mathrm{H}, 8,1.2)\end{array}$ & 120.4 & $\begin{array}{c}7.86 \\
(\mathrm{dd}, 1 \mathrm{H}, 8,1.2)\end{array}$ & 120.4 & $\begin{array}{c}7.86 \\
(\mathrm{dd}, 1 \mathrm{H}, 8,1.2)\end{array}$ \\
\hline 9 & 137.8 & $7.73(\mathrm{t}, 1 \mathrm{H}, 8)$ & 137.9 & $7.73(\mathrm{t}, 1 \mathrm{H}, 8)$ & 137.7 & $7.73(\mathrm{t}, 1 \mathrm{H}, 8)$ & 137.7 & $7.72(\mathrm{t}, 1 \mathrm{H}, 8)$ \\
\hline 10 & 136.0 & $\begin{array}{c}7.35 \\
(\mathrm{dd}, 1 \mathrm{H}, 8,1.2)\end{array}$ & 125.2 & $\begin{array}{c}7.34 \\
(\mathrm{dd}, 1 \mathrm{H}, 8,1.2)\end{array}$ & 125.1 & $\begin{array}{c}7.35 \\
(\mathrm{dd}, 1 \mathrm{H}, 8,1.2)\end{array}$ & 125.1 & $\begin{array}{c}7.33 \\
(\mathrm{dd}, 1 \mathrm{H}, 8,1.2)\end{array}$ \\
\hline 11 & 160.3 & & 160.6 & & 160.0 & & 160.3 & \\
\hline 12 & 115.5 & & 115.6 & & 115.3 & & 115.8 & \\
\hline 13 & 192.8 & & 193.6 & & 181.2 & & 192.7 & \\
\hline 14 & 115.8 & & 115.8 & & 115.8 & & 115.8 & \\
\hline 15 & 162.8 & & 162.8 & & 162.8 & & 162.8 & \\
\hline 16 & 130.4 & & 133.0 & & 136.6 & & 132.5 & \\
\hline 17 & 206.7 & & 184.4 & & 205.8 & & 184.2 & \\
\hline 18 & 42.4 & $3.04(\mathrm{t}, 2 \mathrm{H}, 7)$ & 103.4 & $6.06(\mathrm{~s}, 1 \mathrm{H})$ & 42.3 & $3.04(\mathrm{t}, 2 \mathrm{H}, 7)$ & 103.2 & $5.92(\mathrm{~s}, 1 \mathrm{H})$ \\
\hline 19 & 32.5 & $1.65-1.60(\mathrm{~m}, 2 \mathrm{H})$ & 196.0 & & 32.3 & $1.67-1.58(\mathrm{~m}, 2 \mathrm{H})$ & 195.3 & \\
\hline 20 & 27.8 & $1.78-1.70(\mathrm{~m}, 1 \mathrm{H})$ & 37.4 & $2.44(\mathrm{t}, 2 \mathrm{H}, 8)$ & 27.8 & $1.78-1.69(\mathrm{~m}, 1 \mathrm{H})$ & 36.6 & $2.41(\mathrm{t}, 2 \mathrm{H}, 8)$ \\
\hline 21 & 22.5 & $0.94(\mathrm{~d}, 6 \mathrm{H}, 6)$ & 34.8 & $1.60-1.56(\mathrm{~m}, 2 \mathrm{H})$ & 22.5 & $0.94(\mathrm{~d}, 6 \mathrm{H}, 6)$ & 33.6 & $1.59-1.53(\mathrm{~m}, 2 \mathrm{H})$ \\
\hline 22 & & & 28.1 & $1.70-1.62(\mathrm{~m}, 1 \mathrm{H})$ & 52.5 & $3.714(\mathrm{~s}, 3 \mathrm{H})$ & 28.1 & $1.66-1.61(\mathrm{~m}, 1 \mathrm{H})$ \\
\hline 23 & & & 22.4 & $0.94(\mathrm{~d}, 6 \mathrm{H}, 6)$ & & & 22.8 & $0.93(\mathrm{~d}, 6 \mathrm{H}, 6.5)$ \\
\hline 25 & & & & & & & 52.5 & $3.71(\mathrm{~s}, 3 \mathrm{H})$ \\
\hline
\end{tabular}

${ }^{a}$ Spectra were obtained at $500 \mathrm{MHz}$ for proton and $125 \mathrm{MHz}$ for carbon and were recorded in $\mathrm{CDCl}_{3}$.

${ }^{b}$ Carbons are labeled as shown in Scheme 1. 